\begin{tabular}{|c|c|c|c|c|c|c|}
\hline \multirow{4}{*}{ Impact Factor: } & ISRA (India) & $=3.117$ & SIS (USA) & $=0.912$ & ICV (Poland) & $=6.630$ \\
\hline & ISI (Dubai, UAE & $=0.829$ & РИНЦ (Russia & $=0.156$ & PIF (India) & $=1.940$ \\
\hline & GIF (Australia) & $=0.564$ & ESJI (KZ) & $=8.716$ & IBI (India) & $=4.260$ \\
\hline & JIF & $=1.500$ & SJIF (Morocco & $=5.667$ & OAJI (USA) & $=0.350$ \\
\hline
\end{tabular}

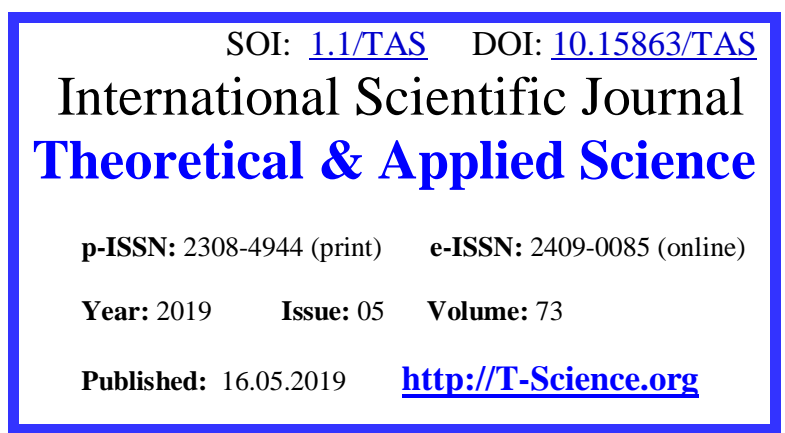

UDC 681.869
QR - Issue

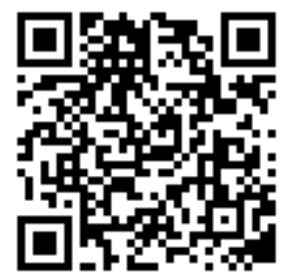

QR - Article

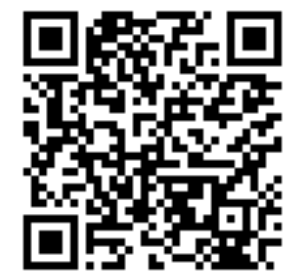

Seysenbek Zaurbekovich Kazakbaev Candidate of technical Sciences, corresponding member RAM, Taraz state pedagogical University seisen58@mail.ru

Nurlan Syrymbaevich Karymsakov Candidate of technical Sciences, Taraz state University named after M.Kh.Dulati nurkar@mail.ru

Nurzhan Karabayev Senior lecturer of Economics Department, Taraz state University named after M.Kh.Dulati

Nurzhan_444@bk.ru

Alexandr Shevtsov Candidate of technical Sciences, Associate Professor, Department of Mathematics, Taraz state University named after M.Kh.Dulati Shev_AlexXXXX@mail.ru

\title{
THE GRAIN THROWER-CLASSIFIER FOR GRAIN PROCESSING
}

Abstract: Developed "grain thrower-classifier" superior in quality and performance with foreign counterparts due to lower costs from combining the process of reception and primary processing of grain. The use of the proposed "grain Thrower-classifier" in addition to purification from harmful impurities is accompanied by pre-drying, which has a positive effect on the safety of grain stocks.

Key words: grain, impurity, processing.

Language: Russian

Citation: Kazakbaev, S. Z., Karymsakov, N. S., Karabayev, N., \& Shevtsov, A. (2019). The grain throwerclassifier for grain processing. ISJ Theoretical \& Applied Science, 05 (73), 86-90.

Soi: http://s-o-i.org/1.1/TAS-05-73-16 Doi: crossef https://dx.doi.org/10.15863/TAS.2019.05.73.16

\section{ЗЕРНОМЕТАТЕЛЬ-КЛАССИФИКАТОР ДЛЯ ПЕРЕРАБОТКИ ЗЕРНА}

Аннотация: Разработанный «Зернометатель-классификатор» превосходит по качеству работьл и производительности зарубежным аналогам за счет снижения затрат от совмещения процесса приема и первичной переработки зерна. Использование предлагаемого «Зернометатель-классификатора» помимо очистки от вредных примесей сопровождается предварительной сушкой, что положительно влияет на сохранность хлебных запасов.

Ключевые слова: зерно, примесь, переработка.

\section{Introduction}

Зернометптель-классификатор предназначен для перекидки, перегрузки зерна и очистки преимущественно зерна и зернистых продуктов от крупных, металломагнитных, легких примесей и пыли, а также для обеззараживания зернопродуктов, предварительной сушки зерна, и может быть использовано на предприятиях системы хлебопродуктов, в сельском хозяйстве и других отраслях промышленности. 


\begin{tabular}{|c|c|c|c|c|c|c|}
\hline \multirow{4}{*}{ Impact Factor: } & ISRA (India) & $=3.117$ & SIS (USA) & $=0.912$ & ICV (Poland) & $=6.630$ \\
\hline & ISI (Dubai, UAE & $=0.829$ & РИНЦ (Russia & $=0.156$ & PIF (India) & $=1.940$ \\
\hline & GIF (Australia) & $=0.564$ & ESJI (KZ) & $=8.716$ & IBI (India) & $=4.260$ \\
\hline & JIF & $=1.500$ & SJIF (Morocce & $=5.667$ & OAJI (USA) & $=0.350$ \\
\hline
\end{tabular}

\section{Materials and Methods}

Известны «Зернометатель-классификатор», по патенту №1919 на полезную модель [1] и «Зернометатель-классификатор», состоящий из зернометателя и пневмороторного классификатора, особенностью которого является то, что пневмороторный классификатор [2] установлен на зернометателе между скребковым конвейером и ленточным метателем, что позволит совместить перегрузочные операции с технологическими, как очистка зерна от крупных, металломагнитных, легких примесей и пыли, а также как обеззараживание зерна по инновационному патенту РК № 24531 от 15.09.2011, бюл. № 9, [3]. Недостатоком данных «Зернометателей-классификаторов» является ограниченная фукциональность.

Известны востребованные в сельском хозяйстве «Зернометатели ЗМ» [4] предназначенные для загрузки и разгрузки зерноскладов, механического перелопачивания зерна на площадках зернотоков, для формирования буртов зерна и погрузки в транспортные средства, сепарации зерна с отделением легких примесей, состоящие из

Техническим результатом в полезной модели является то, что на нижний короб в половой полости загрузочного транспортера «Зернометатель-классификатор»

устанавливается просеивающие сита с приемником мелких примесей, а в потолочой полости вмонтирован индукционный электрический канальный нагреватель, а также с торцевой стороны патрубка приемника мелких примесей установлен сервисный люк и смотровое окно, что позволит совместить перегрузочные операции с технологическими, как очистка зерна от мелких примесей, а так же как обеззараживание и предварительная сушка зерна. Сита установленные в нижней половой полости короба загрузочного транспортера является просеивающим элементом для мелких примесей. Вмонтированный в потолочой полости индукционный электрический канальный нагреватель способствует эффективно производить обеззараживание и обеспечить предварительную сушку зерна. Для визуального загрузочного транспортера с двумя Т-образно расположенными питателями, триммера и ходовой части с электроприводами.

Недостаток этих «Зернометателей»: низкая технологическая эффективность отделения легких примесей из-за отсутствия пневмотехнологических классифицирующих устройств.

В предлогаемом «Зернометптельклассификаторе» эти недостатки устранены за счет введения некоторых технических новшеств в конструкции машины описанных ниже.

Задача и технический результат полезной модели заключается в расширении технологических возможностей «Зернометателяклассификатора».

Данная задача достигается за счет того, что на нижний короб в половой полости загрузочного транспортера «Зернометатель-классификатор» устанавливаются просеивающие сита с приемником мелких примесей, а в потолочой полости вмонтирован индукционный электрический канальный нагреватель. В патрубке приемника мелких примесей с торцевой стороны установлен совмещенный сервисный люк со смотровым окном.

наблюдения процесса просеивания мелких примесей предусмотрены сервисный люк и смотровое окно.

Сущность полезной модели поясняется чертежом. На фиг.1 изображена принципиальная схема «Зернометателя-класификатора», который состоит из «Зернометателя ЗМ» 6 и «Пневмороторного классификатора ПРК» 7. Основными элементами «Зернометателяклассификатора» являются загрузочный транспортер 3 с двумя Т-образно расположенными питателями 1 и триммер 8. Загрузочный транспортер 3 включает нижний короб 10, в половой полости которого устанавлены просеивающие сита 4 с приемником мелких примесей 9, а в потолочой полости вмонтирован индукционный электрический канальный нагреватель 2. С торцевой стороны приемника мелких примесей 9 установлен совмещенный сервисный люк 5 со смотровым окном. 


\begin{tabular}{llllll} 
& ISRA (India) $=\mathbf{3 . 1 1 7}$ & SIS (USA) & $=\mathbf{0 . 9 1 2}$ & ICV (Poland) & $=\mathbf{6 . 6 3 0}$ \\
Impact Factor: & ISI (Dubai, UAE) $=\mathbf{0 . 8 2 9}$ & PUHL (Russia) $=\mathbf{0 . 1 5 6}$ & PIF (India) & $=\mathbf{1 . 9 4 0}$ \\
& GIF (Australia) $=\mathbf{0 . 5 6 4}$ & ESJI (KZ) & $=\mathbf{8 . 7 1 6}$ & IBI (India) & $=\mathbf{4 . 2 6 0}$ \\
& JIF & $\mathbf{1 . 5 0 0}$ & SJIF (Morocco) $=\mathbf{5 . 6 6 7}$ & OAJI (USA) & $\mathbf{0 . 3 5 0}$ \\
\hline
\end{tabular}

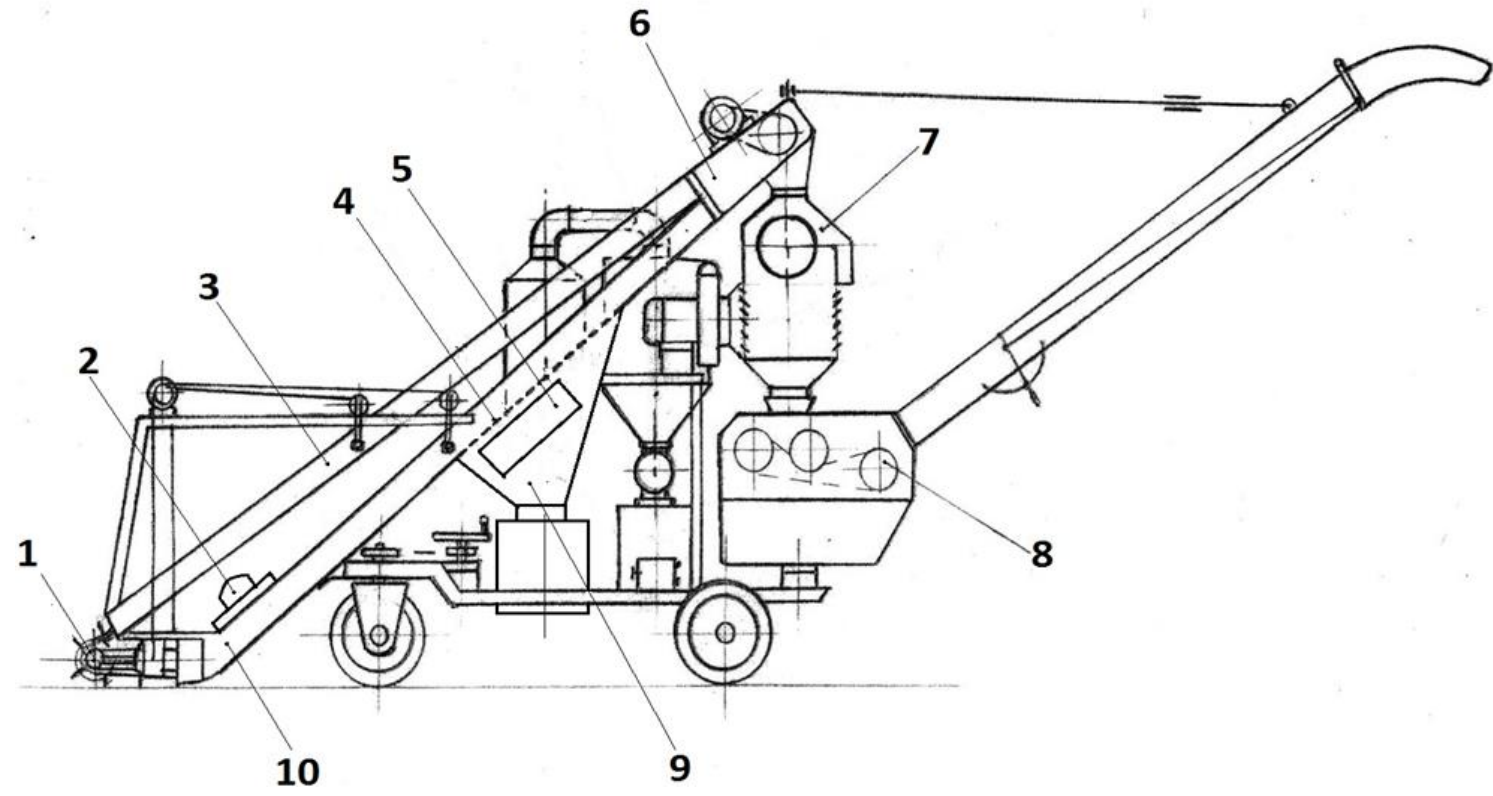

Рис.1. «Зернометатель-классификатор»

«Зернометатель-классификатор» работает следующим образом. Зерно с Т-образного питателя 1 поступает на нижний короб 10 загрузочнго транспортера 3, которая подвергается воздействию ТВЧ с потолочой полости от индукционного электрического канального нагревателя 2. При этом лучи ТВЧ целенаправлено и эффективно воздействуют на транспортируемую зерновую массу, подвеагая нагреву, что способствует предварительной сушке и обеззараживанию зерна от вредителей хлебных запасов и насекомых. Мелкие примеси с зерновой массы транспортируемой по нижнему коробу попутно просеиваются через сита 4, установленные в половой полости нижнего короба 10 загрузочного транспортера 3. Очищенные от мелких примесей зернопродукты поступают на «Пневмороторный классификатор ПРК» 7, гле отделяются крупные и легкие примеси, в том числе пыль и насекомые. Далее очищенное от примесей зерновая масса с разгрузочного патрубка классификатора 7 поступают на бесконечную ленту триммера 8 .

Применение

«Зернометателяклассификатора» на токах крестъянских хозяйств и на складах хлебоприемных предприятий позволит выполнить очистку зерна от мелких, крупных, металломагнитных, легких примесей и пыли, а также от вредителей хлебных запасов непосредственно в процессе приемки, транспортирования и переработки продукта. При этом сокращаются капитальные и эксплуатационные затраты на приемку и обработку продуктов.

Преимуществом

предлагаемого

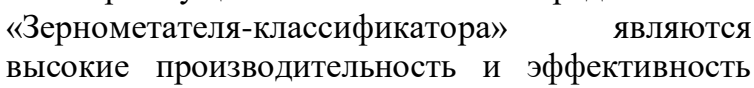
очистки зернопродуктов от мелких, крупных, легких примесей и пыли, а также совмещение траноспортных операций с технологическими, такими как обеззараживание зерна, предварительная сушка.

Отличительной особенностью «Зернометателя-классификатора» от аналогов является расширение технологических возможностей машины, простота конструкции и удобства сервисного обслуживания.

Результатом ННТД является разработанное универсальное инновационное устройство «Зернометатель-классификатор», позволяющий одновременно и высокоэффективно производить перегрузочные операции совместно с технологическими, такие как очистка зерна от мелких, крупных, металломагнитных, легких примесей и пыли. Совмещение перекидки и предварительной очистки зерна позволит зернопроизводителям в первую очередь сохранить драгоценное время во время уборки, эффективно и своевременно производить послеуборочную обработку, сократить эксплуатационные расходы на приемку и обработку зерна и тем самым создать благоприятные условия для сушки и хранения зерна.

Например, при использовании традиционной техники эксплуатационные расходы 


\begin{tabular}{llllll} 
& ISRA (India) $=\mathbf{3 . 1 1 7}$ & SIS (USA) $=\mathbf{0 . 9 1 2}$ & ICV (Poland) & $\mathbf{= 6 . 6 3 0}$ \\
Impact Factor: & ISI (Dubai, UAE) $=\mathbf{0 . 8 2 9}$ & PUHЦ (Russia) $=\mathbf{0 . 1 5 6}$ & PIF (India) & $=\mathbf{1 . 9 4 0}$ \\
& GIF (Australia) $=\mathbf{0 . 5 6 4}$ & ESJI (KZ) & $\mathbf{8 . 7 1 6}$ & IBI (India) & $=\mathbf{4 . 2 6 0}$ \\
& JIF & $\mathbf{1 . 5 0 0}$ & SJIF (Morocco) $=\mathbf{5 . 6 6 7}$ & OAJI (USA) & $\mathbf{0 . 3 5 0}$ \\
\hline
\end{tabular}

зернопроизводителя для очистки 1 тонны зерна составляют 4300 тенге: свежеубранное зерно $\Rightarrow$ «Зернометатель» $\Rightarrow$ погрузка автомобль $\Rightarrow 3 \mathrm{AB}-40 \Rightarrow$ выгрузка на автотранспорт $\Rightarrow$ склад.

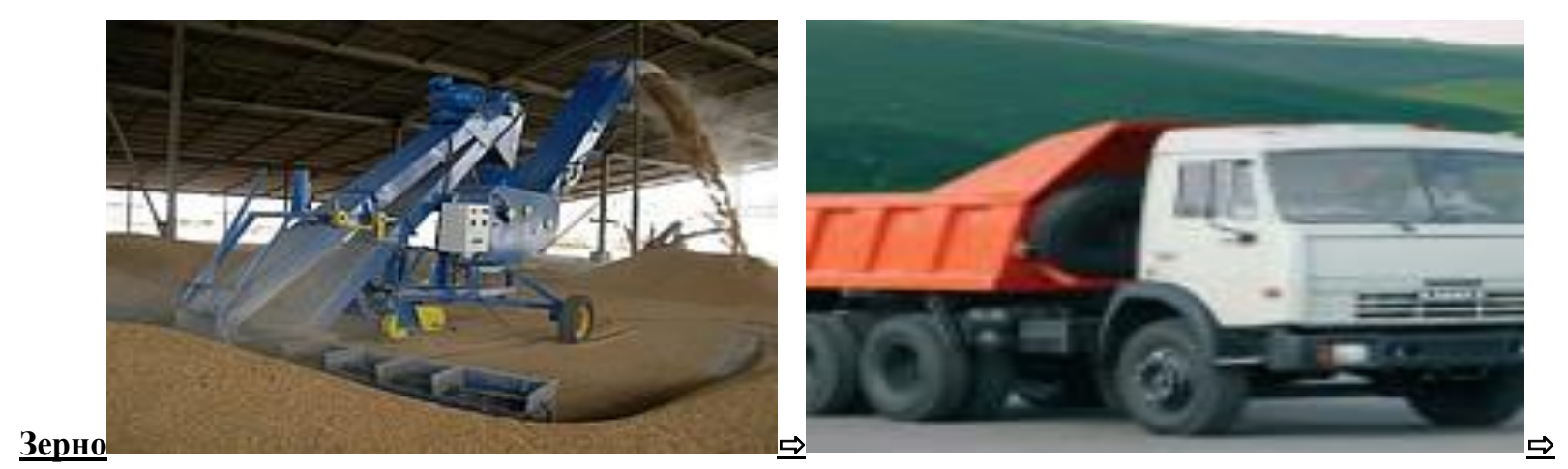

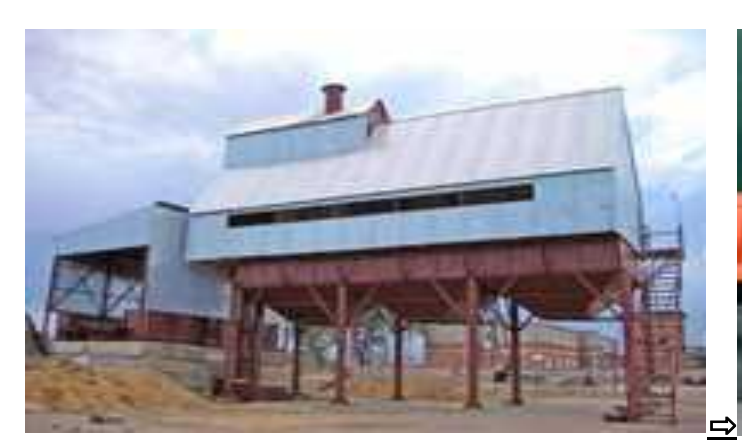

При использовании «Зернометателяклассификатора» эксплуатационные расходы для очистки 1 тонны зерна составляют 1700 тенге, то есть в 2,53 раза ниже чем при использовании традиционной техники: свежеубранное зерно $\Rightarrow$

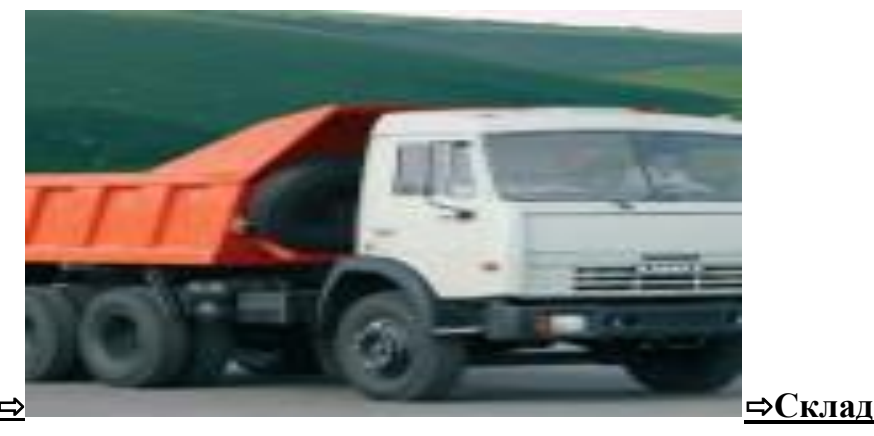

«Зернометатель-классификатор» $\Rightarrow$ погрузка на автомобль $\Rightarrow$ склад. В предлагаемом случае минуется 2 операции: очистка зерна ЗАВом и выгрузка на автотранспорт.

\section{Зерно $\Rightarrow$}

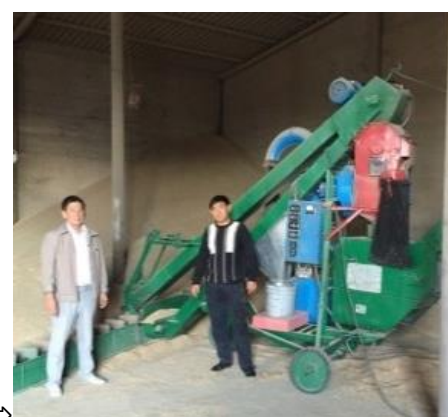

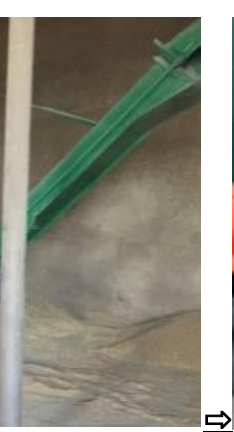

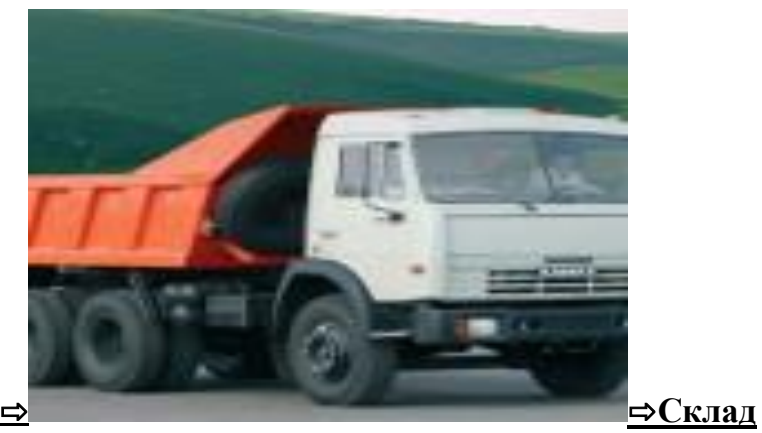

Выгоды всех зернопроизводящих предприятий от внедрения «Зернометательклассификатора» заключаются в сокращении приведённых затрат в 2,5 раза на 1 тонну перерабатываемого зерна за счёт повышения производительности и эффективности очистки от крупных, металломагнитных, лёгких примесей и пыли, а также от вредителей хлебных запасов. Практически все крестьянские и фермерские хозяйства получат выгоду от внедрения «Зернометатель-классификатора» и технологии как минимум на 1600000 тенге за сезон уборки урожая, так как они надежны в эксплуатации, просты по конструкции, имеют низкие приведенные затраты

Практической ценностью результатов научной деятельности являются:

-экспериментально

подтверждены эффективность очистки зерна от легких примесей способом расслоения зерна и равномерностью его распределения по площади поперечного сечения пневмосепарирующей камеры [5]; 


\begin{tabular}{llllll} 
& ISRA (India) $=\mathbf{3 . 1 1 7}$ & SIS (USA) & $=\mathbf{0 . 9 1 2}$ & ICV (Poland) & $=\mathbf{6 . 6 3 0}$ \\
Impact Factor: & ISI (Dubai, UAE) $=\mathbf{0 . 8 2 9}$ & PUHL (Russia) $=\mathbf{0 . 1 5 6}$ & PIF (India) & $=\mathbf{1 . 9 4 0}$ \\
& GIF (Australia) $=\mathbf{0 . 5 6 4}$ & ESJI (KZ) & $=\mathbf{8 . 7 1 6}$ & IBI (India) & $=\mathbf{4 . 2 6 0}$ \\
& JIF & $\mathbf{1 . 5 0 0}$ & SJIF (Morocco) $=\mathbf{5 . 6 6 7}$ & OAJI (USA) & $\mathbf{0 . 3 5 0}$ \\
\hline
\end{tabular}

-оптимизированы технологические режимы процесса очистки зерна от крупных и легких примесей [6];

-разработаны исходные требования на экспериментальный образец «Зернометательклассификатор» [7];

\section{Conclusion}

В инновационной технике и технологии для послеуборочной обработки зерна востребованы практически все зернопроизводящие и зерноперерабатывающие предприятия РК и стран СНГ. Как показывают прогнозные расчеты, применение в производстве предлагаемого «Зернометатель-классификатор» для послеуборочной обработки зерна позволит получить годовую экономию совокупных затрат денежных средств 1176 тыс. тенге (на один агрегат) в сравнении с действующими зерноочистительными комплексами.

Положительным результатом проекта является то, что потребитель получит менее дорогой и способный работать в различных ресурсосберегающих системах послеуборочной обработки зерна очистительный комплекс. Разработанный «Зернометатель-классификатор» превосходит по качеству работы и производительности зарубежным аналогам за счет снижения затрат от совмещения процесса приема и первичной переработки зерна. Использование предлагаемого «Зернометатель-классификатор» помимо очистки от вредных примесей сопровождается предварительной сушкой, что положительно влияет на сохранность хлебных запасов.

\section{References:}

1. (2016). Patent № 1919 na poleznuyu model' «Zernometatel'-klassifikator». Zar. v Gos. reestre PM RK ot 12.12.2016g. Udostoverenie avtora № 95862 poleznoy modeli «Zernometatel'-klassifikator» ot 19.10.2015 g.

2. (2010). A.S. № 65792, RK, innovatsionnyy patent № 23126 na izobretenie «Pnevmorotornyy klassifikator» ot 20.09.2010g.

3. (2011). A.S. № 70124, RK, innovatsionnyy patent № 24531 na izobretenie «Zernometatel' klassifikator» ot 03.08.2011g.

4. (n.d.). Zernometateli ZM-60 i R6-MZS-100

5. Kazakbaev, S. Z., Karymsakov, N. S., Seytpanov, P. K., \& Bekmuratov, M. M. (2014). Innovative techology postharvest processing grain. ISJ Theoretical \& Applied Science, 05, (13): 69-77. doi: http://dx.doi.org/10.15863/TAS.2014.05.13.11

6. Kazakbaev, S. Z., Karymsakov, N. S., Seytpanov, P. K., Bekmuratov, M. M., \&
Shevtsov, A. N. (2014). Creating a complex innovative machinery grain processing. ISJ Theoretical \& Applied Science, 05, (13): 78-83. doi:

http://dx.doi.org/10.15863/TAS.2014.05.13.12

7. Kazakbaev, S. Z., Karymsakov, N. S., Madaliyeva, E. B., \& Shevtsov, A. N. (2015). Grain caster classifier for post-harvest processing of grain. ISJ Theoretical \& Applied Science 05 (25): 88-94. Soi: http://s-oi.org/1.1/TAS*05(25)18 Doi: http://dx.doi.org/10.15863/TAS.2015.05.25.18

8. Kazakbaev, S. Z., Karymsakov, N. S., Bekmuratov, M. M., Shevtsov, A. N., Son, I. A., \& Son, V. A. (2016). The grain throwerclassifier for pre-cleaning grain. ISJ Theoretical \& Applied Science, 04 (36): 76-82. Soi: http://so-i.org/1.1/TAS-04-36-11 Doi: http://dx.doi.org/10.15863/TAS.2016.04.36.11 
ISRA (India) $\quad \mathbf{=} \mathbf{3 . 1 1 7}$

Impact Factor: $\quad$ ISI (Dubai, UAE) $=\mathbf{0 . 8 2 9}$

GIF (Australia) $=\mathbf{0 . 5 6 4}$

JIF

$=1.500$
SIS (USA)

РИНЦ $($ Russia $)=\mathbf{0 . 1 5 6}$

ESJI $($ KZ) $\quad=\mathbf{8 . 7 1 6}$

SJIF $($ Morocco $)=\mathbf{5 . 6 6 7}$
ICV (Poland)

PIF (India)

IBI (India)

$=6.630$ 
ISRA (India) $\quad \mathbf{=} \mathbf{3 . 1 1 7}$

Impact Factor: $\quad$ ISI (Dubai, UAE) $=\mathbf{0 . 8 2 9}$

GIF (Australia) $=\mathbf{0 . 5 6 4}$

JIF

$=1.500$
SIS (USA)

РИНЦ $($ Russia $)=0.156$

ESJI $($ KZ) $\quad=\mathbf{8 . 7 1 6}$

SJIF $($ Morocco $)=\mathbf{5 . 6 6 7}$
ICV (Poland)

PIF (India)

IBI (India)

$=6.630$ 